\title{
A case of metronidazole-induced central and peripheral nervous system complications
}

\author{
Ning Wu, Joseph Nguyen and Aiesha Ahmed* \\ Departments of Neurology, Penn State College of Medicine, Hershey Medical Center, Hershey, PA, USA
}

\begin{abstract}
While metronidazole is a fairly safe and well tolerated antibiotic, it can rarely cause serious neurological adverse events, including polyneuropathy, cerebellar dysfunction, ototoxicity, seizures, visual impairment, and encephalopathy. Here we report a case of a 22-year-old male, who was treated for 2-month with metronidazole for brain abscess leading to the presentation of polyneuropathy, encephalopathy, ataxia and seizures. The Magnetic resonance imaging (MRI) of the brain revealed abnormal signal intensity involving bilateral cerebellar lobes. The electrodiagnostic study showed an axonal sensorimotor polyneuropathy. His symptoms gradually improved after cessation of metronidazole with complete recovery of central nervous system manifestation in one month along with MRI resolution of cerebellar signal changes. However, the sensorimotor polyneuropathy related symptoms persisted. This case illustrates metronidazole as a rare cause of concurrent central and peripheral nervous system complications after long term treatment. The diagnosis of metronidazole toxicity was made by MRI, electrodiagnostic findings and supported clinically. The treatment is cessation of assaulting agent and medical support which in our patient led to resolution of most symptoms.
\end{abstract}

\section{Introduction}

Metronidazole is a commonly used antibiotic with potent activity against anaerobic bacteria and protozoa. It is believed to cross bloodbrain-barrier and penetrate central nervous system easily. While metronidazole is fairly safe and well tolerated, it can rarely cause serious neurological adverse events, including peripheral neuropathy, cerebellar dysfunction, ototoxicity, seizures, visual impairment, and encephalopathy $[1,2]$. It has been suggested that neurological toxicity may be related to prolonged administration, high doses, or high cumulative doses of metronidazole [3]. Here we report clinical course, MRI as well as electrodiagnostic findings consistent with concurrent central nervous system (CNS) and peripheral nervous system (PNS) complications in a patient on metronidazole.

\section{Case report}

A 22-year-old male was diagnosed with brain abscess after he presented with new onset seizure disorder. He underwent ethmoidectomy and maxillary sinusectomy with growth of grampositive cocci in cluster and was treated with antibiotics including intra venous (IV) metronidazole, ceftriaxone, and linezolid. The initial brain MRI showed a cystic lesion measuring about $1 \mathrm{~cm}$ in diameter with some enhancement within a nodule on the wall, consistent with a brain abscess. He did not have significant neurological deficit initially except the generalized fatigue and subjective memory impairment.

One month later, he developed progressive pain, numbness and tingling in bilateral lower extremities in a stocking- pattern. Linezolid was therefore switched to vancomycin which was discontinued 10 days later due to persistent symptoms. Metronidazole and ceftriaxone were continued for another month until he developed encephalopathy, recurrent seizure, ataxia, and severe gait dysfunction about 2 months after the initial presentation and was admitted for further evaluation. The pertinent exam findings revealed a lethargic young male with difficult concentrating, and short-term memory impairment. His sensory exam revealed diminished light touch, pinprick, vibration, proprioception, with hypersensitivity to temperature in distal extremities in glove stocking distribution. Hyperreflexia was noted throughout. Fingerto-nose testing revealed mild ataxia in both arms. He also had truncal ataxia and was not able stand up without assistance. A repeat brain MRI showed decreased size of previously noted abscess with new foci of abnormal enhancement along bilateral cerebellar lobes and pons (Figure 1A). The Electromyography/nerve conduction studies (EMG/

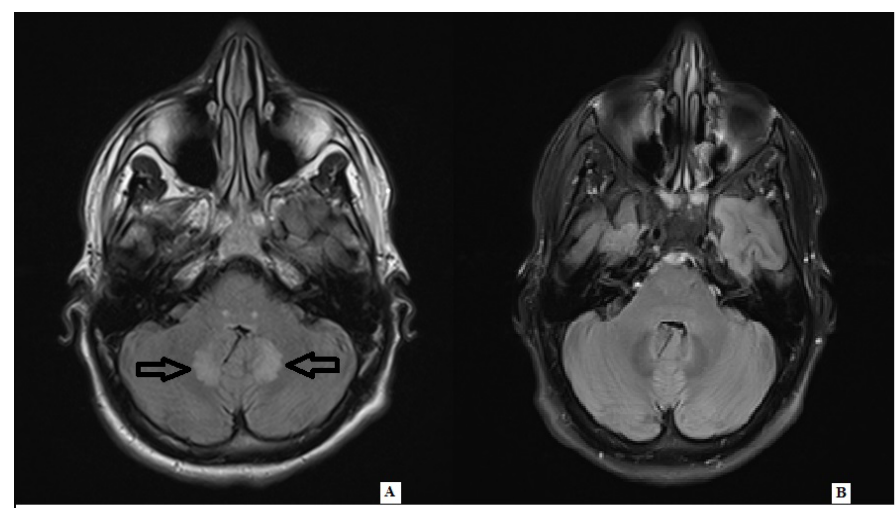

Figure 1. A) T2 flair revealed hyperintensity in bilateral pons and cerebellar lobes. B) T2 flair revealed interval complete resolution of the pons and cerebellar signal abnormality one month after discontinuation of metronidazole.

Correspondence to: Aiesha Ahmed, Departments of Neurology, Penn State College of Medicine, Hershey Medical Center, Hershey, PA, USA, Tel: 717-5311802; Fax: 717-531-0384; E-mail: aahmed1@hmc.psu.edu

Key words: central nervous system, electrodiagnostic study, magnetic resonance imaging, metronidazole, peripheral neuropathy

Received: January 21, 2016; Accepted: February 16, 2016; Published: February 21,2016 
NCS) revealed electro-diagnostic evidence of a chronic moderate to severe sensorimotor polyneuropathy with ongoing denervation in distal muscles (Tables 1 and 2). The blood work included unremarkable thyroid function, syphilis antibody, Lyme's antibodies, vitamin B1, B6, B12, immune-fixation test, and serum protein electrophoresis. Etiology was considered to be metronidazole use. Metronidazole was immediately discontinued given the concern of toxicity. At one month follow-up, he was able to walk without any support. His neurologic exam revealed improvement of previously noted CNS abnormalities. Follow up MRI showed interval complete resolution of cerebellar signal changes (Figure 1B).

\section{Discussion}

Our patient developed central and peripheral nervous system complications with chronic metronidazole treatment and improved after discontinuation. His central nervous symptoms improved significantly one month after discontinuation of metronidazole, which was evident with the interval complete resolution of cerebellar signal changes on follow up MRI. The polyneuropathy, however, continued to persist at the follow up visit based on the abnormal exam and electrodiagnostic study.

The pathogenesis of metronidazole neurotoxicity is currently

Table 1.

\begin{tabular}{|c|c|c|c|c|c|c|}
\hline Nerve & $\begin{array}{c}\text { Sensory } \\
\text { Distal } \\
\text { Latency } \\
(\mathrm{ms})\end{array}$ & \begin{tabular}{|c|} 
Sensory \\
Distal \\
Amplitude \\
$(\mu \mathrm{V})$
\end{tabular} & $\begin{array}{c}\text { Motor } \\
\text { Distal } \\
\text { Latency } \\
\text { (ms) }\end{array}$ & \begin{tabular}{|c|} 
Motor \\
Distal \\
Amplitude \\
$(\mathbf{m V})$
\end{tabular} & $\begin{array}{c}\text { Motor } \\
\text { Conduction } \\
\text { Velocity } \\
(\mathbf{m} / \mathbf{s})\end{array}$ & $\begin{array}{c}\text { F Wave } \\
\text { Latency } \\
\quad(\mathrm{ms})\end{array}$ \\
\hline Median* & $3.0(<3.7)$ & $6.4(>20.0)$ & $3.0(<4.4)$ & $9.56(>4.0)$ & $55.9(>49.0)$ & $25.6(<31)$ \\
\hline Ulnar* & $2.9(<3.5)$ & $2.7(>10.0)$ & $2.5(<3.5)$ & $11.51(>6.0)$ & $53.9(>49.0)$ & $27.3(<32)$ \\
\hline Radial** & $2.2(<2.9)$ & $8.3(>15.0)$ & & & & \\
\hline Peroneal $\dagger$ & & & $4.1(<6.1)$ & $0.78(>2.0)$ & $42.5(>41.0)$ & \\
\hline Tibial\$ & & & $4.3(<6.1)$ & $0.82(>3.0)$ & $47.1(>41.0)$ & \\
\hline Sural & NR & & & & & \\
\hline $\begin{array}{l}\text { Superficial } \\
\text { peroneal }\end{array}$ & NR & & & & & \\
\hline
\end{tabular}

NR: no response. Normal values are given in parentheses.

*Stimulating wrist, recording digits 2 or 5 (sensory) or recording abductor pollicis brevis or abductor digiti minimi muscle (motor).

**Stimulating forearm, recording anatomical snuff box.

$\uparrow$ Stimulating ankle, recording extensor digitorum brevis muscle.

\#Stimulating ankle, recording abductor hallucis muscle.

Table 2.

\begin{tabular}{|l|l|c|c|c|}
\hline Muscle & & $\begin{array}{c}\text { Right Tibialis } \\
\text { Anterior }\end{array}$ & $\begin{array}{c}\text { Right Gastrocnemius } \\
\text { (Medial head) }\end{array}$ & $\begin{array}{c}\text { Right Extensor } \\
\text { Halluces Longus }\end{array}$ \\
\hline Insert activity & Inset & Normal & Increase & Increase \\
\hline \multirow{4}{*}{$\begin{array}{l}\text { Spontaneous } \\
\text { Activity }\end{array}$} & Fibrillation & None & $2+$ & None \\
\cline { 2 - 6 } & +Waves & None & $2+$ & None \\
\cline { 2 - 6 } & Fasciculation & None & None & None \\
\cline { 2 - 6 } & Other & None & None & None \\
\hline \multirow{3}{*}{$\begin{array}{l}\text { Voluntary } \\
\text { Activity }\end{array}$} & Amplitude & Increase 1+ & Increase 2+ & Normal \\
\cline { 2 - 6 } & Duration & Increase 1+ & Increase 2+ & Normal \\
\cline { 2 - 6 } & Recruitment & Decrease 1+ & Decrease 2+ & Normal \\
\hline \multirow{2}{*}{$\begin{array}{l}\text { Maximal } \\
\text { Voluntary } \\
\text { Activity }\end{array}$} & Activation & Maximal & Maximal & Maximal \\
\hline
\end{tabular}

unknown. Proposed causes include 1) RNA binding with inhibition of protein synthesis and axonal degeneration [4], 2) modulation of inhibitory neurotransmitters the gamma-aminobutyric acid receptors within cerebellar and vestibular systems [4]. Based on the current literature, the toxic range of metronidazole dosage is wide (range of 25 to 1080 grams), and it does not seem to be a dose- or duration-related phenomenon [2,3]. The duration of treatment before developing neurotoxicity is variable ranging from 1 day to 180 days with the average treatment duration around 50-60 days [3,5]. The patient we report here underwent the metronidazole treatment for 1-2 months before developing peripheral neuropathy, encephalopathy and ataxia and received a total metronidazole dose of 134 gram.

The common features of metronidazole-induced neurotoxicity include encephalopathy, cerebellar dysfunction, seizures and peripheral neuropathy, but only a small proportion of patients have more than one manifestation, as the patient in this case report. Abnormalities in MRI are common, with cerebellar dentate lesion present in most images [3]. Abnormalities in MRI can also involve medulla and splenium of the corpus callosum [6]. Most of the detected MRI lesions completely resolved, with rare exception [3,6]. Most of the Diffusion weighted imaging lesions in metronidazole induced encephalopathy probably correspond to areas of vasogenic edema, whereas only some of them, located in the corpus callosum, correspond to cytotoxic edema. There have only been a few case reports of metronidazole-induced peripheral neuropathy with mainly sensory involvement on EMG. The symptoms of peripheral neuropathy can completely or partially resolve $[1,7,8]$. Electrophysiological evaluation usually suggests axonal pattern [9]. Our patient had both sensory and motor axonal polyneuropathy with ongoing denervation in distal muscles. Following discontinuation of metronidazole therapy, clinical improvement was noted in all patients in whom it was reported (generally within 3-7 days) [2]. The symptoms of peripheral neuropathy usually occurred earlier, but recovered slowly compared to the resolutions of CNS manifestations. The average time for peripheral neuropathy to recover ranged from months to years. Some of the cases were supported by EMG/NCS studies which showed complete resolution $[2,9]$.

\section{Conclusion}

Here we report a rare case of metronidazole neurotoxicity after two months treatment with both CNS and PNS manifestations in the form of encephalopathy, ataxia, seizures and polyneuropathy. The diagnosis of metronidazole toxicity was made by clinical, MRIs, and EMG/NCS findings. As our case demonstrates, it is important to be mindful of medication toxicity as potential cause of neurological symptoms, especially in patients with sensorimotor polyneuropathy, which can occur earlier than CNS presentations. The treatment is cessation of offending agent and medical support which in our patient led to improvement.

\section{References}

1. Horlen CK, Seifert CF, Malouf CS (2000) Toxic metronidazole-induced MRI changes. Ann Pharmacother 34: 1273-1275.[Crossref]

2. Patel K, Green-Hopkins I, Lu S, Tunkel AR (2008) Cerebellar ataxia following prolonged use of metronidazole: case report and literature review. Int J Infect Dis 12: e111-114.[Crossref]

3. Kuriyama A, Jackson JL, Doi A, Kamiya T (2011) Metronidazole-induced central nervous system toxicity: a systematic review. ClinNeuropharmacol 34: 241-247. [Crossref]

4. Kim H, Kim YW, Kim SR, Park IS, Jo KW (2011) Metronidazole-induced encephalopathy in a patient with infectious colitis: a case report. J Med Case Rep 5: 63. [Crossref] 
5. Cação G, Fontes S, Salgado M, Rodrigues T, Damásio J (2015) Metronidazole-induced central and peripheral nervous system toxicity. NeurolSci 36: 1737-1739.[Crossref]

6. Hobbs K, Stern-Nezer S, Buckwalter MS, Fischbein N, Finley Caulfield A (2015) Metronidazole-induced encephalopathy: not always a reversible situation. Neurocrit Care 22: 429-436.[Crossref]

7. Cecil KM, Halsted MJ, Schapiro M, Dinopoulos A, Jones BV (2002) Reversible
MR imaging and MR spectroscopy abnormalities in association with metronidazole therapy. J Comput Assist Tomogr 26: 948-951.[Crossref]

8. Kim E, Na DG, Kim EY, Kim JH, Son KR, et al. (2007) MR imaging of metronidazoleinduced encephalopathy: lesion distribution and diffusion-weighted imaging findings. AJNR Am J Neuroradiol 28: 1652-1658.[Crossref]

9. Retamal-Riquelme E, Soto-San Martín H, Vallejos-Castro J, Galdames-Poblete D (2014) [Reversible neurotoxicity secondary to metronidazole: report of one case]. Rev Med Chil 142: 386-390.[Crossref]

Copyright: (C2016 Wu N. This is an open-access article distributed under the terms of the Creative Commons Attribution License, which permits unrestricted use, distribution, and reproduction in any medium, provided the original author and source are credited. 